\title{
The Excretion of Cells in Urine Following Perinatal Asphyxia
}

\author{
K.TAN and D. HulL ${ }^{[13]}$ \\ Institute of Child Health, University of London, England
}

The clinical finding of transient celluria in human infants experiencing perinatal asphyxia stimulated this experimental study on fetal and newborn rabbits. Both fetal and newborn rabbits, asphyxiated to the point of death, failed on recovery to excrete excessive numbers of epithelial cells in urine, whereas fetal rabbits, born of a doe that had been given $10 \%$ oxygen in nitrogen for 60 minutes, and newborn rabbits, given $5 \%$ oxygen in nitrogen for 70 to 90 minutes, excreted excessive numbers of cells in urine during the second to fourth day. This investigation supports the suggestion that perinatal hypoxia can lead to renal damage and reaffirms the need to differentiate epithelial cells from white blood cells in the urine of newborn infants.

\section{Speculation}

Prolonged perinatal asphyxia may cause renal damage. Occasionally, it is severe enough to cause acute renal failure in newborn infants. The possibility that it may cause chronic renal impairment should be explored.

\section{Introduction}

In clinical practice, microscopic examination of urine to determine the number of white blood cells is a wellestablished technique used in the diagnosis of urinary tract infections. In the newborn period, however, such investigation may be misleading, since urine of newborn infants often contains nonsquamous epithelial cells that can be confused with white blood cells, especially if the urine is not examined immediately $[1,10]$. Excessive numbers of epithelial cells have been found in the urine of eight infants who experienced perinatal asphyxia [6]. Since severe intrauterine asphyxia has been known to cause renal tubular necrosis and medullary hemorrhage $[7,12]$, it is possible that the pres- ence of epithelial cells in urine indicates a less severe form of renal damage. To examine this relation, fetal and newborn rabbits were asphyxiated, and urine obtained by suprapubic aspiration was examined serially for ten days.

\section{Methods}

Observations were made on the urine of 17 newborn rabbits following normal births; the other rabbits had experienced asphyxia either immediately before or soon after birth. In Group I, 19 fetuses from 4 does were asphyxiated in utero. The pregnant does were killed at term, 31 days after mating, by a sudden blow on the back of the neck. Circulation was stopped by cut- 
ting open the heart. Two or three of the fetuses were delivered immediately. The remainder were left in utero for 10 to 16 minutes and then were delivered and allowed to recover in air. Preliminary experiments showed that total asphyxia for a longer period of time was usually fatal. Care was taken not to let the fetuses cool during asphyxia.

In Group II, nine fetuses experienced partial asphyxia in utero. Four fetuses were not studied during the experiment. One pregnant doe went into labor spontaneously but after delivering one of her young, failed to produce the remainder and became increasingly distressed. To avoid suffering, the doe was anesthetized, and the remaining fetuses were delivered abdominally. Three were stillborn; one was in the birth canal. All showed signs of severe asphyxia. The rest recovered and were reared satisfactorily with a nursing doe. To simulate this intrauterine hypoxia, a second doe was given $10 \%$ oxygen in nitrogen for 70 minutes on the day of delivery. The fetuses were born 3 hours later.

The fetuses in Groups III and IV were born normally and asphyxiated on the day of birth. In Group III, eight were placed in $100 \%$ nitrogen. These rapidly became unconscious and, after initial respiratory efforts, exhibited apnea. Following the period of apnea, gasping began, increased in frequency, and then suddenly stopped. It was known that if the newborn rabbits were not revived at this time, they would notrecover. The maximum period of total asphyxia that newborn rabbits could tolerate varied between 12 to 18 minutes. In Group IV, 15 newborns were placed in $5 \%$ oxygen in $95 \%$ nitrogen for periods of 70 to 90 minutes at an environmental temperature of $36 \pm 2^{\circ}$. Again, the rabbits became quickly unconscious and limp, but survived and recovered slowly when given air at the end of the experiment.

All rabbits were subsequently reared in a thermoneutral environment and placed in beakers in a water bath kept at $36.5 \pm 1^{\circ}$. They were returned each morning to the cage of the nursing doe for feeding. Each rabbit was weighed before feeding. When 2 to 3 weeks old, they were transferred from the incubators to a metal cage and were allowed to huddle together in a straw nest. The room temperature was regulated between 20 and $23^{\circ}$.

Urine samples were collected by suprapubic aspiration. The suprapubic area was swabbed with $5 \%$ hibitane before aspiration. Most specimens were examined immediately; a few were maintained at $4^{\circ}$ to keep cell disappearance to a minimum and were examined not later than three hours after collection. The $\mathrm{pH}$ of urine was determined by a $\mathrm{pH}$ paper indicator, and the presence of albumin and glucose was determined by uristix. Urine was plated onto blood agar and MacConkey media. Following thorough mixing, the un- centrifuged specimen was examined under the microscope. A drop of glacial acetic acid was added if the specimen appeared turbid. Cell counts were made using a modified Neubauer counting chamber. Each specimen was examined for crystals, casts, and cells. Nonsquamous epithelial cells were differentiated from pus cells by noting morphological characteristics [1, 10]. Initially, a differential staining technique [11] was employed, but the preceding method proved to be just as reliable. Urine obviously contaminated by blood caused by trauma during suprapubic aspiration was discarded.

\section{Results}

Repeated suprapubic aspiration of urine of rabbits delivered normally or by cesarean section did not lead to a rise in excretion of epithelial cells. Figure 1 shows the epithelial cell count in the urine of 17 newborn rabbits that had not been asphyxiated at birth. Usually, the urine was found to contain less than 20 cells/ $\mathrm{mm}^{3}$, but occasionally $40 \mathrm{cells} / \mathrm{mm}^{3}$ were found. Squamous cells and red blood cells were scanty or absent; hyaline casts were occasionally seen. Oxalate and phosphate crystals were often found after the third day of life. The $\mathrm{pH}$ of urine varied from 5.0 to 9.0, but usually fell between 6.0 to 8.0. No glucose was found; albumin was always less than $10 \mathrm{mg} / 100 \mathrm{ml}$.

\section{Intrauterine Asphyxia}

The urine of the 19 fetuses in Group I that experienced total asphyxia did not contain epithelial cells (fig. 2); the subsequent rate of growth was normal (fig.5). In contrast, the urine of the fetuses of the doe that was unable to complete spontaneous delivery contained increased numbers of epithelial cells (fig. 3). In two fetuses, the urine contained more than 200 epithelial cells $/ \mathrm{mm}^{3}$. The duration of asphyxia experienced by these fetuses is unknown.

The urine of five fetuses experimentally exposed to hypoxia in utero also contained excessive numbers of epithelial cells. The scatter was fairly wide; for clarity, only the means and SE of means are shown in figure 2. In both of the last two groups of observations, the increase in epithelial cells was accompanied by an increased excretion of hyaline and cellular casts, and 'aged' red blood cells, presumably of renal origin, were frequently seen.

\section{Neonatal Asphyxia}

The urine of the eight newborn rabbits that were asphyxiated with pure nitrogen to the point of death did not differ from that of nonasphyxiated littermates (fig.4); but of the fifteen newborn rabbits that were given $5 \%$ oxygen in nitrogen to breathe for $70-90$ 


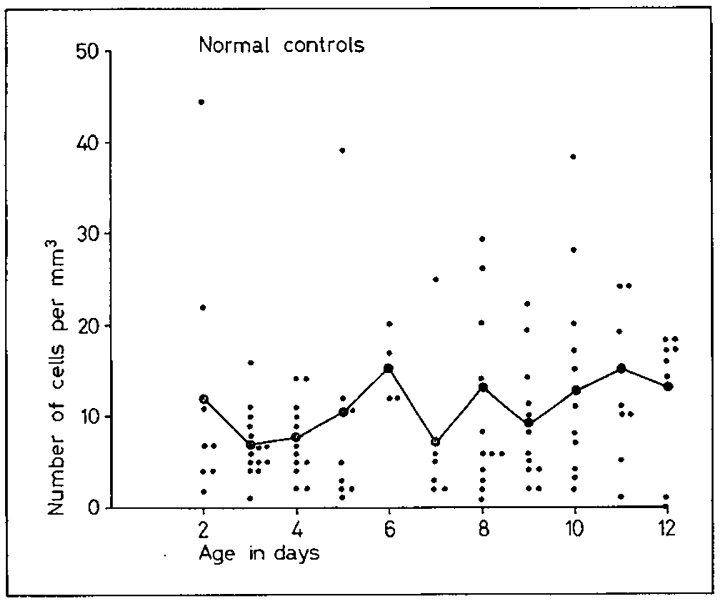

Fig. 1. The number of nonsquamous epithelial cells in the urine of newborn rabbits that were not asphyxiated. The large dots joined by the line give the mean values for each day.

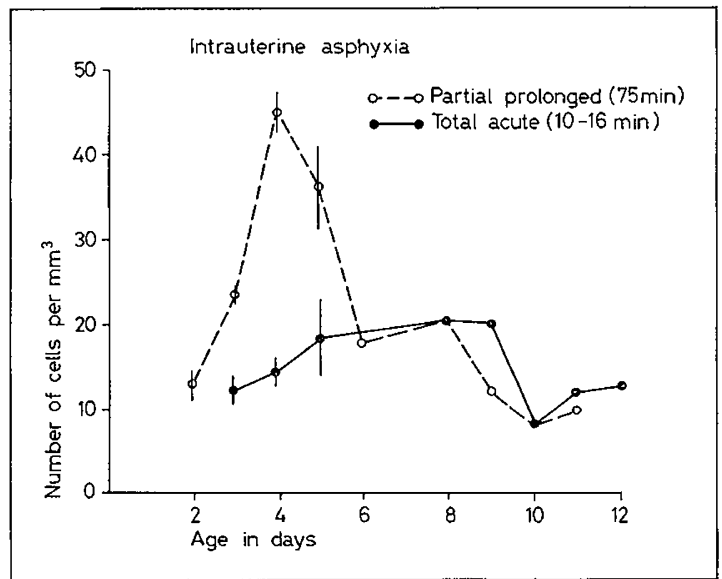

Fig. 2. The effect of intrauterine total acute asphyxia and partial prolonged hypoxia on the cellular excretion of newborn rabbits. Each dot represents the mean of cell counts of urine from five or more rabbits. The vertical line is the $\mathrm{SE}$ of the mean.

minutes, ten excreted excessive numbers of cells (over 50 cells $/ \mathrm{mm}^{3}$ ). The mean cell count in the urine of all fifteen rabbits is shown in figure 4. This celluria was accompanied by hyaline and cellular casts with 'aged' red blood cells, but the glucose and albumin content was not increased. The subsequent rate of growth of these rabbits was normal (fig. 5).

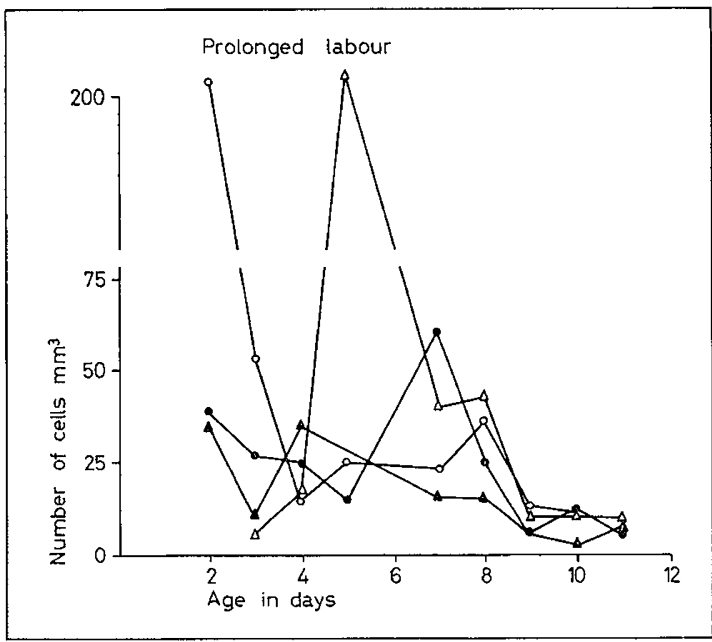

Fig.3. Cell excretion in the urine of four rabbits after prolonged intrauterine asphyxia.

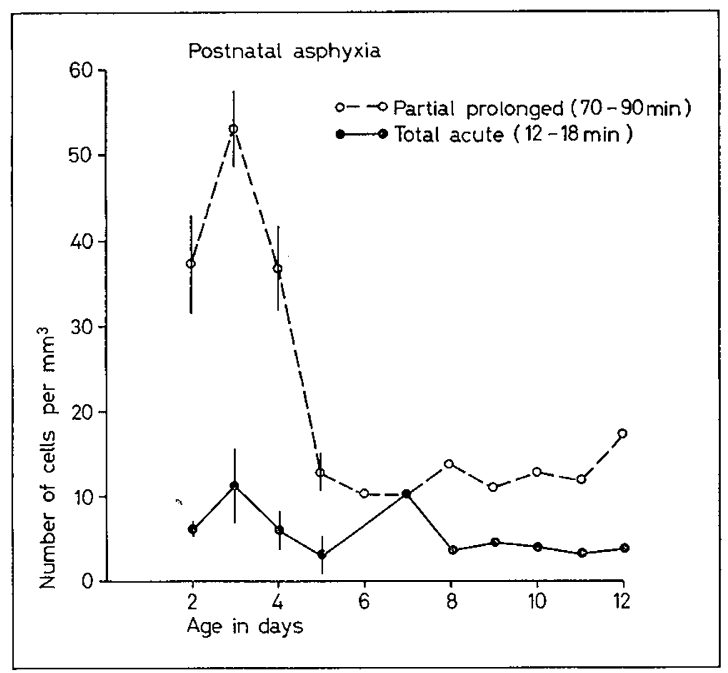

Fig. 4. The effect of postnatal asphyxia on the cellular excretion of newborn rabbits. Each dot represents the mean of cell counts of urine from six or more rabbits. The vertical line is the SE of the mean.

\section{Suprapubic Aspiration}

In the course of this study, 930 suprapubic aspirations were performed. Urine of only eight rabbits became infected, and these rabbits were excluded from the study. Thus, the incidence of infection was only $0.85 \%$. The organisms cultured were coagulase negative Staphylococcus on four occasions, and E. coli, Strepto- 


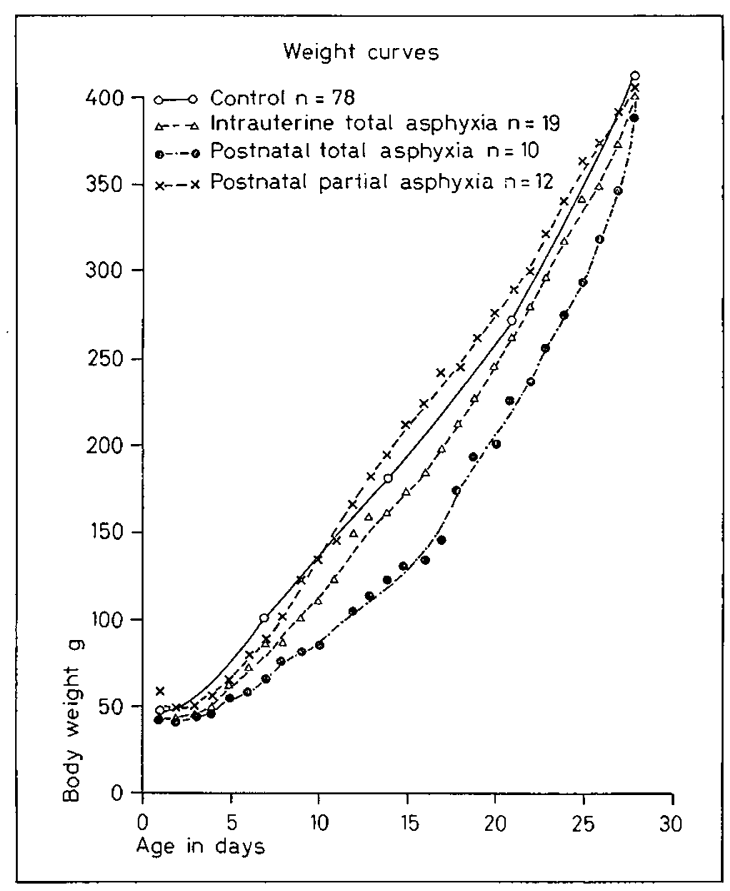

Fig. 5. The weight curves of fetal and newborn rabbits subject to asphyxia, compared with those of control animals.

coccus faecalis, coagulase-positive Staphylococcus, and Candida albicans, each on one occasion. The growth of organisms on culture was accompanied by an increase in the number of white blood cells in the urine.

\section{Discussion}

In adults, severe asphyxia leads to a fall in cardiac rate and output; the vessels to the viscera and limbs constrict in order to increase blood flow and maintain the oxygen supply to the brain and heart. The mature fetus reacts to asphyxia in essentially the same way as does the adult; however, it is more sensitive than is the mother to a decrease in the level of ambient oxygen [2]. Thus, with asphyxia, the decreased rate of blood flow to the kidneys leads to a consequent change in renal function $[4,5,9]$. Compared with other organs, particularly the brain, the kidney withstands total asphyxia well. It is probably for this reason that the limit to which fetal and newborn rabbits could tolerate total asphyxia did not lead to an increase in epithelial cell excretion. During partial asphyxia, however, when circulatory adjustments are adequate to maintain the circulation and oxygen supply to the brain and the heart, the kidney is at risk. In the fetal and newborn rabbits exposed to partial asphyxia, the increased number of epithelial cells excreted was accompanied by hyaline and cellular casts and aged red cells.

These findings strongly suggest that the kidneys were damaged by asphyxia and are of clinical interest for two reasons. First, they support the hypothesis that the presence of epithelial cells in the urine of a human newborn infant indicates that prolonged asphyxia was experienced either before or after birth [6]. It is probable that this asphyxia represents a mild expression of a whole range of renal damage that can occur in the infant. Severe asphyxia has been reported to cause nephrosis [8], renal tubular necrosis [3, 7], and massive medullary hemorrhage [12] in newborn infants. Furthermore, a transient macroscopic hematuria following intrauterine asphyxia is a common clinical observation. It is possible that in some infants, asphyxia is the cause of chronic renal failure soon after birth. Some may recover or some may subsequently die; hypoplastic kidneys may be found at necropsy.

Second, this transient celluria caused by epithelial cells should be differentiated from celluria caused by white blood cells secondary to urinary tract infection. The high excretion of epithelial cells observed by HALVORSEN and AAS [6] persisted from 2 to 10 days. In the present study, epithelial cells appeared only during the first five days of life, but the asphyxia experienced by the rabbits may have been for a shorter duration than that which has been experienced by human infants under adverse obstetric conditions. Suprapubic aspiration is being used increasingly in clinical practice. It is encouraging to find that in conditions in which skin antisepsis has been difficult, infection has been rarely introduced.

Although the newborn rabbits in this study experienced severe sublethal total asphyxia or prolonged partial asphyxia, the rate of growth was normal and it was impossible, by careful observation of their movement and behavior, to distinguish them from their littermates.

\section{Summary}

The excessive numbers of epithelial cells occasionally found in the urine of newborn infants have been suggested to be a consequence of renal damage caused by intrauterine asphyxia. To investigate this hypothesis, fetal and newborn rabbits were asphyxiated, and urine was examined daily for ten days. It was found that prolonged partial asphyxia caused epithelial celluria, but acute total asphyxia did not. This finding supports the hypothesis that intrauterine asphyxia can cause renal damage. It is important in clinical practice to differentiate celluria caused by white blood cells from that caused by epithelial cells. 


\section{References and Notes}

1. AAs, K.: The cellular excretion in the urine of normal infants. Acta paediat. scand. 50: 36 (1961).

2. Assali, N.S.; Holm, L.W. and Sehgal, N.: Haemodynamic changes in foetal lambs in uteno in response to asphyxia, hypoxia and hypercapnea. Circulat. Res. 11: 423 (1962).

3. Bernstein, J.: Renal tubular and pancreatic islet necrosis in newly born infants. Amer.J. Dis. Child. 96: 705 (1958).

4. Cosgrove, M. D.: The effect of arterial hypoxia on the blood flow through the renal cortex. Brit.J. Surg. 52: 613 (1965).

5. Gomori, P.; Kovach, A.G.B.; TAkcs, L.; Foldi, M.; SzABo, G.V. and NAGY, Z.: Renal blood flow in arterial hypoxia. Acta med. Acad. Sci. hung. 16: 37 (1960).

6. Halverson, S. and Aas, K.: Observation on the urine of asphyxiated and dysmature newborn infants. Acta. paediat.scand. 51: 447 (1962).

7. Jonsson, B. : Lower nephron nephrosis in asphyxia neonatorum. Acta.paediat. scand. 40: 401 (1957).

8. Kessel, L. and Pepler, W.J.: Lower nephron nephrosis in the newborn. J.obstet. Gynaec. brit. Emp. 62: 98 (1955).

9. KoRNer, P.I.: Effects of hypoxia on the renal circulation. Bull. post-grad. Comm. Med. Univ. Sydney 20: 67 (1964).

10. Kwitthen, J. and Rerner, L.: Acute tubular nephrosis in the newborn infant, a manifestation of anoxia. Pediatrics 33: 380 (1964).

11. Prescott, L.F. and Brodie, D. E. : A simple differential stain for urinary sediment. Lancet ii: 940 (1964).

12. Thomas, M.A.: Perinatal hemorrhagic necrosis of renal pyramids. Amer. J. Dis. Child. 108: 13 (1964).

13. Requests for reprints should be sent to: David HuLL, M.B., Institute of Child Health, University of London, 30, Guilford Street, London, W.C.1 (England). 